\title{
Comparing the potential for dispersal via waterbirds of a native and an invasive brine shrimp
}

\author{
MARTA I. SÁNCHEZ*, FRANCISCO HORTAS ${ }^{\dagger}$, JORDI FIGUEROLA* AND ANDY J. GREEN* \\ *Department of Wetland Ecology, Estación Biológica de Doñana (CSIC), Seville, Spain \\ ${ }^{\dagger}$ Department of Biology, Faculty of Marine and Environmental Sciences, Cádiz University, Puerto Real, Spain
}

\section{SUMMARY}

1. Migratory waterbirds are likely to have a major role in the spread of many exotic aquatic invertebrates by passive dispersal. However, in the field, this has so far only been confirmed in the case of the American brine shrimp Artemia franciscana, which is spreading quickly around the Mediterranean region.

2. We compared experimentally the capacity of A. franciscana and the native brine shrimp Artemia parthenogenetica to disperse via migratory shorebirds. After Artemia resting eggs (cysts) were fed to Redshank Tringa totanus and Dunlin Calidris alpina, we compared the proportion that survived gut passage, their hatchability and their retention time within the gut. We also tested the ability of cysts to stick to the feathers of Black-tailed Godwit Limosa limosa.

3. The proportion of ingested cysts retrieved from faeces was the same for each Artemia species (8\%), and there were no significant differences in retention time (mean $1.2 \mathrm{~h}$ and maximum $10 \mathrm{~h}$ for A. parthenogenetica, 1.4 and $12 \mathrm{~h}$ for A. franciscana) or hatchability (11\% versus $14 \%$ ). The two shorebird species showed similar retention times and retrieval rates, but cysts recovered from Dunlin had a significantly higher hatchability. Only one of the 1000 A. parthenogenetica cysts and three of the $1000 \mathrm{~A}$. franciscana cysts stuck to feathers.

4. These results indicate that both non-native and native brine shrimps have a similar high capacity for endozoochory via birds, and that the invasiveness of A. franciscana is probably explained by its competitive superiority owing to high fecundity and release from cestode parasitism. Owing to their different migratory behaviour, Redshank and Dunlin are likely to have different roles as brine shrimp vectors. Brine shrimps provide a suitable model for understanding the role of birds in the dispersal of exotic aquatic invertebrates.

Keywords: Artemia franciscana, dispersal ability, Endozoochory, Epizoochory, retention time

\section{Introduction}

Exotic invertebrates are spreading across the world's aquatic ecosystems, with major economic consequences and impacts on indigenous biodiversity (Strayer, 2010). It has been argued that passive dispersal by migratory waterbirds plays an important role in the spread of invasive invertebrates, especially those with resistant propagules that can be transported externally or within the avian gut (Figuerola \& Green, 2002a; Green \& Figuerola, 2005). Similarly, a broad range of exotic plants are known to be dispersed by waterbirds (Green et al., 2008; Brochet et al., 2009). However, to date, such transport of exotic invertebrates in the field has been demonstrated only for the American brine shrimp Artemia franciscana Kellogg, whose resting eggs (or cysts) are abundant in the faeces and pellets of shorebirds at invaded salt pans in the Iberian Peninsula (Green et al., 2005).

Following their importance for use as nursery food in aquaculture, A. franciscana is spreading quickly around the Mediterranean region and other parts of the world, and displacing native brine shrimps including the sexually reproducing Artemia salina and a group of clonal Artemia, often grouped under the name A. parthenogenetica Bowen \& Sterling (Amat et al., 2005; Van Stappen et al., 2007; Muñ oz

Correspondence: Andy J. Green, Department of Wetland Ecology, Estación Biológica de Doñana (CSIC), Avda. Américo Vespucio s/n, 41092 Seville, Spain. E-mail: ajgreen@ebd.csic.es 

\& Pacios, 2010). This displacement is thought to have had a negative impact on natural cestode parasites of Artemia, which appear unable to switch to the exotic host (Georgiev et al., 2007). It may also reduce the foraging intake of birds using hypersaline wetlands, since they feed selectively on Artemia infected with cestodes (Sanchez et al., 2009).

Different hypotheses have been proposed to explain the capacity of invasive invertebrates to colonise quickly and outcompete native species. Among other factors, invasive species may flourish by escaping their natural enemies and parasites (Wolfe, 2002) and have a high population growth rate, short generation time and high dispersal ability (Williamson, 1996; Whitney \& Gabler, 2008). The rapid spread of invasive organisms does indicate a high dispersal capacity (Williamson, 1996). In this study, to account for the rapid spread of $\mathrm{A}$. franciscana, we present experiments to compare its dispersal potential via migratory shorebirds with that of the native A. parthenogenetica. We also compared the ability of the cysts of these two taxa to survive passage through the gut of migratory shorebirds, as well as their retention time, and their ability to become attached to feathers as shorebirds move around hypersaline habitats in which cysts are floating. We test the hypotheses that cysts of the invader are: (i) more likely to survive gut passage, (ii) more likely to hatch after retrieval from faeces, (iii) have a longer retention time within the gut, thus facilitating long-distance dispersal and (iv) have a greater propensity to become attached to feathers of shorebirds. We also compared the potential of two different shorebirds, varying in body size and migratory behaviour, as vectors for endozoochory: the Redshank Tringa totanus Linnaeus and Dunlin Calidris alpina Linnaeus. We predicted that cyst retention time would be longer in Redshank, owing to its larger size (Hahn, Bauer \& Klaassen, 2008).

\section{Methods}

Fresh, intact cysts were collected in August 2005 at sites in Spain where native and invasive Artemia are under long-term study. Artemia parthenogenetica was collected from the Odiel salt ponds near Huelva (Sanchez, Green \& Castellanos, 2006a for detailed description). Artemia franciscana were collected from La Tapa salt ponds near Puerto de Santa María in Cadiz Bay. Species identification has repeatedly been confirmed from these study areas by morphological and genetic criteria (Amat et al., 2005; Muñ oz et al., 2010). The A. parthenogenetica at Odiel are predominantly diploid with a small percentage of tetraploid individuals, but we had no way of separating these in our sample.
In the laboratory, cysts were washed using distilled water (0.1-mm mesh sieve), dried for $24 \mathrm{~h}$ at $40{ }^{\circ} \mathrm{C}$ and then stored in the dark at $5^{\circ} \mathrm{C}$. To test the capacity of the two Artemia species to survive passage through the gut of migratory shorebirds, four Redshank (T. totanus) and six Dunlin (C. alpina) were captured in mist nets at El Pilar saltpans (Cádiz) in September-October 2005. These species, like Black-tailed Godwit (Limosa limosa Linnaeus, see below), are known to be habitual consumers of Artemia cysts in the wild (Green et al., 2005; Sanchez, Green \& Castellanos, 2005). Experiments were carried out in Jerez Zoo, Spain in two phases on 8 September [four T. totanus and one C. alpina) and 6 October 2005 (five C. alpina)]. Licences and permits to catch the birds and to conduct the experiments were provided by Dirección General de Gestion del Medio Natural, Consejería de Medio Ambiente, Junta de Andalucía. The experimental design and procedures aimed to minimise the stress to the captive birds. Birds were previously acclimated to captivity in cylindrical cages (1.5 m diameter, $1 \mathrm{~m}$ high) divided into four compartments (one per bird) and covered by a 5-mm mesh net, allowing birds to maintain visual contact. Birds were kept outdoors under natural light for 1 week and provided with food (Nereis polychaetes) ad libitum.

For the feeding experiment, birds were placed indoors in individual boxes of $80-55-53 \mathrm{~cm}$, one side being made from a 1-cm mesh net. Tissue paper was placed in the bottom of the cages to collect fresh faeces. Each bird was force-fed 1000 cysts using a syringe and administering a small amount of water $(0.5 \mathrm{~mL})$ to avoid regurgitation. Cysts remaining in the syringe were counted and discarded. Faeces were then collected at regular intervals (every $30 \mathrm{~min}$ for $0-2 \mathrm{~h}$, every hour from 2 to $6 \mathrm{~h}$, every $2 \mathrm{~h}$ from 6 to $14 \mathrm{~h}$ and then every $4 \mathrm{~h}$ until $24 \mathrm{~h}$ had passed since ingestion). Each individual bird was used only once and was fed either A. parthenogenetica or A. franciscana cysts. Half of the individuals of each bird species were fed with each of the brine shrimp species. Once the experiment was finished, birds were kept in captivity for 1 week to ensure that no cysts of A. franciscana remained in the digestive tract and were then liberated at the original place of capture.

On the day of collection, faeces were washed in the laboratory on a $0.1-\mathrm{mm}$ sieve and resuspended in filtered hypersaline brine, which caused cysts to float. Intact cysts were retrieved and counted. The tissue paper used to collect faeces was also inspected for the presence of additional cysts. Immediately following cyst recovery, the hatchability of retrieved cysts was determined by placing them in a Petri dish (no more than 30 cysts per dish) filled with filtered diluted brine $\left(28 \mathrm{~g} \mathrm{~L}^{{ }^{1}}\right)$ and 
incubated in a climate chamber at $25^{\circ} \mathrm{C}$ under continuous light. The hatchability of control cysts from the same source was also assessed for comparison, using 20 replicates/Petri dishes per Artemia species, 10 containing 20 cysts and 10 containing 40 cysts each. Hatching was checked every day for the next 3 days. We considered that a cyst had hatched when it reached the 'umbrella' stage as the nauplius larva was emerging (Lavens \& Sorgeloos, 1996). It is likely that many of the cysts that failed to hatch were viable, and lack of aeration meant that hatching success was probably suboptimal (Lavens \& Sorgeloos, 1996).

Statistical analyses were performed using the GLIMMIX procedure (SAS Institute Inc., 2008) with a binomial error distribution and a logit link function. Survival of gut passage (defined as retrieval in an apparently intact state) by cysts ( 0 or 1 ) was analysed as the dependent binomial variable and Artemia and bird species as independent fixed factors. Hatching success of cysts (0 or 1$)$ was analysed as the dependent binomial variable in separate analyses with Artemia, bird species, retention time and treatment (ingested by birds or control) as independent factors. In all analyses, statistical values were adjusted for model dispersion, while 'individual bird' was included as a random factor to control for pseudoreplication of cyst data coming from the same specimen. Retention time was compared between Artemia species and bird species using a gamma error distribution and logarithmic link function and fitting each individual bird as a random factor.

In a separate experiment, we used four Black-tailed Godwits found dead in Andalusia and frozen for later preparation as museum specimens. Breast feathers were removed after defrosting. Brine $\left(100 \mathrm{~g} \mathrm{~L}^{{ }^{1}}\right)$ collected from an Odiel salt pond where Artemia and shorebirds are abundant was placed in a Petri dish, and then 50 cysts were floated on the brine. Holding a feather by the quill, it was then moved around amongst the cysts for $5 \mathrm{~s}$ with the convex side (which faces away from the bird under natural conditions) in contact with the water surface. The feather was removed and was then shaken five times by hand before inspection under a binocular microscope to count the number of cysts attached. The number of cysts remaining in the Petri dish were also counted, to establish how many cysts became attached initially but were lost during shaking.

This protocol was repeated 20 times each for cysts of the two Artemia species (source as above), using a different feather and different cysts each time. For each species, five different feathers were used from each of the four godwits. Differences between species were compared using a Mann-Whitney U-test carried out using Statistica 6.0 (StatSoft Inc., 2001).

\section{Results}

Artemia cysts were recovered from the faeces of all shorebirds apart from one C. alpina (which had ingested A. franciscana). Some of the cysts retrieved hatched from the other five C. alpina, as well as from one T. totanus which had ingested A. franciscana. In total, 4074 cysts of A. parthenogenetica were ingested, of which $8.4 \%$ were retrieved (Table 1). Similarly, a total of 3714 cysts of A. franciscana were ingested, of which $8.1 \%$ were retrieved. No statistically significant differences were found between Artemia species $\left(\mathrm{F}_{1,7}=0.01, \mathrm{P}=0.91\right)$ or bird species $\left(\mathrm{F}_{1,7}=1.38, \mathrm{P}=0.28\right)$ in the proportion of ingested cysts that were retrieved, although there was greater retrieval from C. alpina (Table 1).

Table 1 Mean $( \pm \mathrm{SE})$, mode, median and maximum retention time (in h) for retrieved $(\mathrm{R})$ and hatched $(\mathrm{H})$ cysts, and percentages retrieved and hatched for bird-ingested (I) and control (C) cysts. The experiment ended at $24 \mathrm{~h}$. Hatchability is the percentage of intact cysts that hatched within 3 days

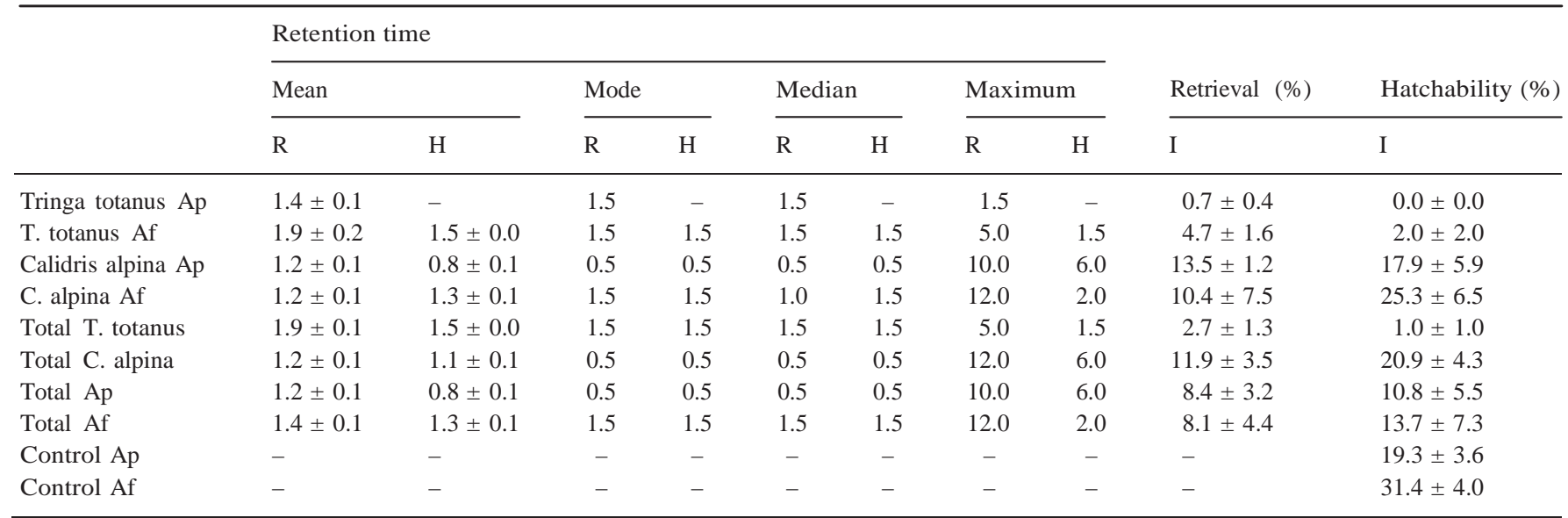


Retrieved cysts (11-14\%) had a lower hatchability than controls (19-31\%, Table 1), but not significantly so $\left(F_{1,45}=2.67, P=0.11\right)$. Similarly, there was no significant difference in hatchability between Artemia species $\left(\mathrm{F}_{1,45}=\right.$ $0.78, \mathrm{P}=0.38$ ), and no interaction between Artemia species and treatment (control or ingested, $\mathrm{F}_{1,45}=1.06, \mathrm{P}=0.31$ ). However, when analysing only cysts ingested by birds, cysts retrieved from C. alpina had a higher hatchability than those from $\mathrm{T}$. totanus $\left(\mathrm{F}_{1,6}=7.84, \mathrm{P}=0.03\right)$.

Cysts were retained in the gut for up to $12 \mathrm{~h}$ (Table 1). The mean retention time of retrieved cysts from a given bird was not related either to Artemia species $\left(F_{1,6}=0.66\right.$, $\mathrm{P}=0.45$; Fig. 1$)$ or to bird species $\left(\mathrm{F}_{1,6}=0.95, \mathrm{P}=0.37\right.$; Fig. 2). Of the cysts recovered, $84.3 \%$ of A. parthenogenetica and $89.6 \%$ of A. franciscana cysts were retrieved within $2 \mathrm{~h}$ of ingestion (Fig. 1). Hatchability of retrieved cysts did not vary significantly with retention time $\left(\mathrm{F}_{1,585}=0.05\right.$, $P=0.82$ ). This result did not change when controlling for
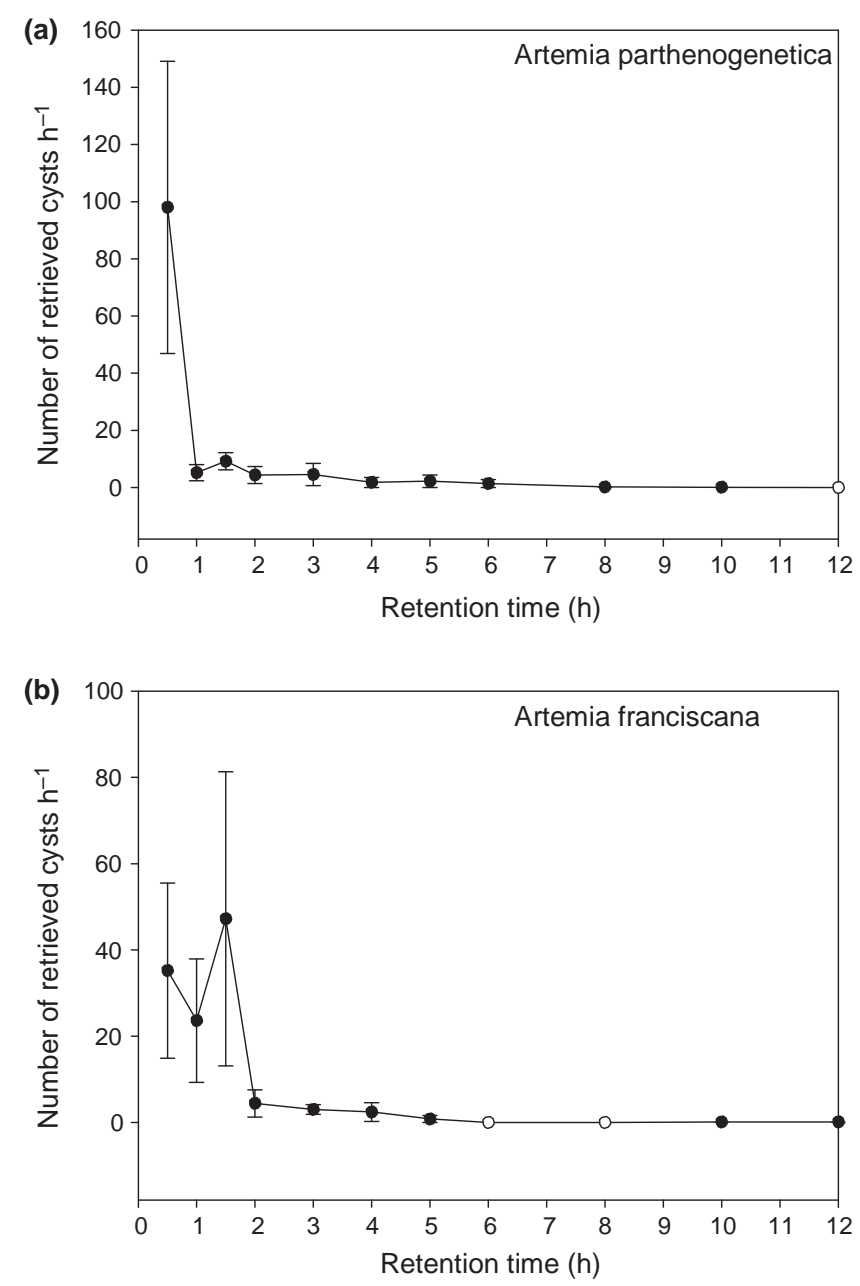

Fig. 1 Retention time for intact cysts of (a) Artemia parthenogenética and (b) Artemia franciscana. Data represent mean values \pm SE for different individual birds. White circles represent time intervals when no cysts were recovered.
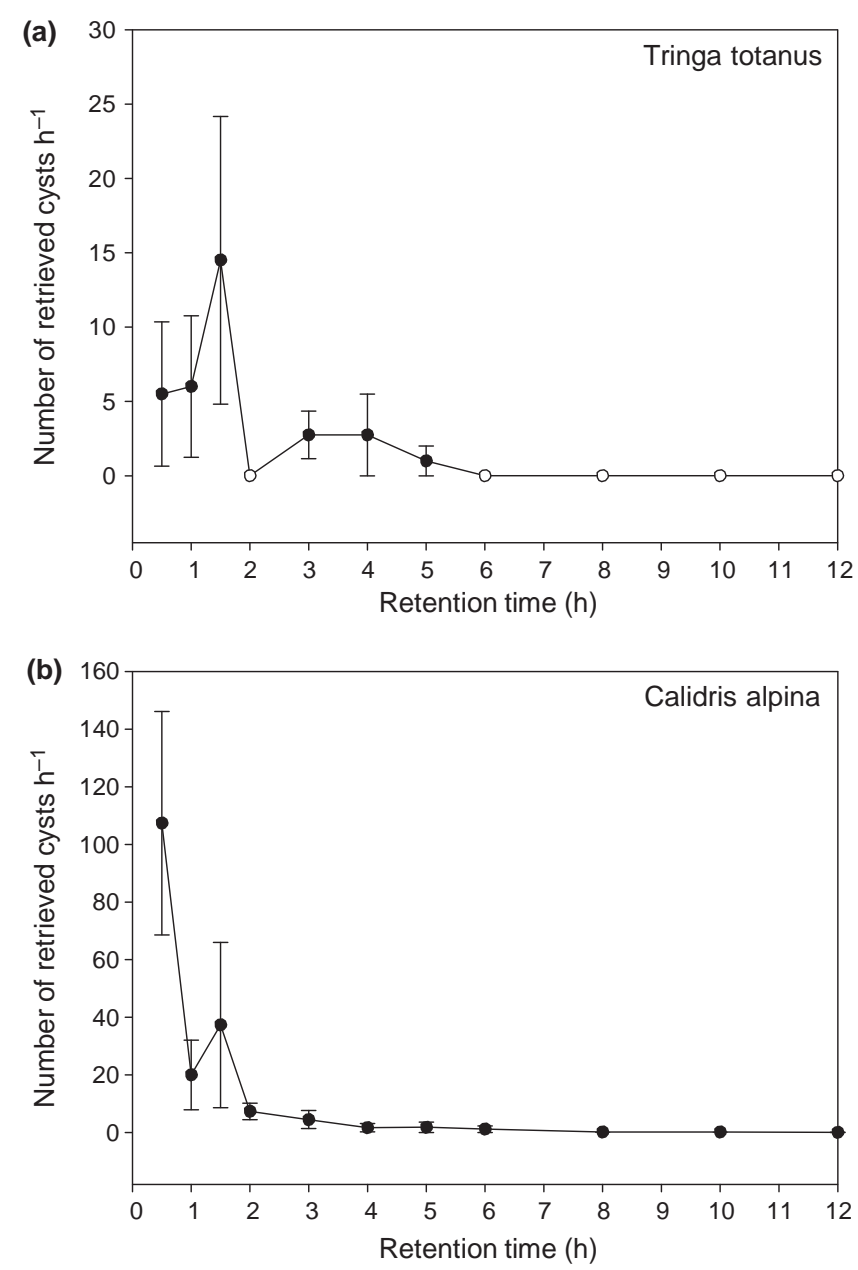

Fig. 2 Retention time of intact Artemia cysts for (a) Tringa totanus and (b) Calidris alpina. Data represent mean values \pm SE for different individual birds. White circles represent time intervals when no cysts were recovered.

Artemia and /or bird species $\left(\mathrm{F}_{1,585} £ 0.10, \mathrm{P} \ddagger 0.75\right)$, nor when fitting retention time as a quadratic function to allow for curvilinear relationships $\left(F_{1,584} £ 2.48, P \ddagger 0.12\right)$.

From the 40 trials involving 2000 cysts, initial attachment to feathers was recorded on five feathers involving a total of five cysts of A. parthenogenetica (on three feathers) and three of A. franciscana. After shaking, a total of one cyst of A. parthenogenetica and three of A. franciscana (on two feathers) remained attached. Differences between Artemia species were not significant (Mann-Whitney U-test, $\mathrm{P}>0.5$ ).

\section{Discussion}

There is an increasing interest in the role of birds as vectors of other organisms (Sekercioglu, 2006). To the best of our knowledge, this is the first study to compare the 
retention time, survival and viability of the propagules of two invertebrates at the same time. Various studies have carried this out with seeds (Espinar et al., 2004; Brochet et al., 2010c; Figuerola et al., 2010). Malone (1965) compared the viability of eggs of two gastropod species after passing through the gut of ducks, but did not study retention time.

There was a great deal of variation between individual birds in retention time, the proportion of cysts that passed through the gut, and the proportion that hatched. In field conditions, the proportion of cysts destroyed decreases when shorebirds ingest fewer bivalves and other hard food items, and when they ingest a larger number of cysts (Sanchez et al., 2007). High variability between individual birds is typical in experiments in which seeds are retrieved from waterbird faeces (Brochet et al., 2010c; Figuerola et al., 2010) and led us to find few statistically significant differences, even when mean values were very different between treatments (Table 1). Similarly, no significant differences were observed between duck species in retrieval over time of propagules of the bryozoan Cristatella mucedo Cuvier or of the cladoceran Bythotrephes longimanus Leydig (Charalambidou, Ketelaars \& Santamaría, 2003a; Charalambidou, Santamaría \& Figuerola, 2003b), although these studies only used three or four individuals of each bird species.

Although invertebrate propagules can be transported externally on waterbirds (Brochet et al., 2010a), this study suggests that internal transport is more important for Artemia cysts, as also suggested for seeds transported by ducks (Brochet et al., 2010b). Cysts are smooth spheres and, although they float at the surface after release in salt ponds where waterbirds are swimming or feeding, our experiment suggests they have little propensity to stick to feathers. On the other hand, cysts form concentrations on the shoreline downwind, and birds may carry cysts on their feet with the help of sticky mud (Figuerola \& Green, 2002b).

Both Artemia taxa are clearly capable of surviving passage through the gut, as previously indicated by the abundance of viable cysts in faeces collected from the field (Green et al., 2005; Sanchez et al., 2007). We found no evidence of differences in survival, retention time or hatchability between native and exotic Artemia. Hence, they may have a similar potential for dispersal by waterbirds that ingest cysts directly, or by preying on females with cysts in their ovisacs. Field observations suggest that shorebirds mainly ingest cysts by the latter mechanism (Sanchez et al., 2007). Our results suggest that the invasiveness of $\mathrm{A}$. franciscana in the Mediterranean region is aided by a strong potential to disperse by waterbirds, but that this is no greater than in the native Artemia. Other studies suggest that the invader can outcompete native Artemia by a combination of greater fecundity and release from natural parasites (Amat et al., 2007; Georgiev et al., 2007). However, our study cannot be considered a general test of the difference in dispersal potential between native and exotic invertebrates.

Artemia franciscana is also spread on cars or boots of people moving between salt pans (Waterkeyn et al., 2010). Genetic studies suggest that diploid A. parthenogenetica originated within the last 12000 years in central Asia and spread quickly across the Mediterranean region, with birds being the most likely vector (Muñ oz et al., 2010). They were able to exploit the numerous coastal salt pond complexes created around the Mediterranean for salt extraction since Roman times.

Cysts retrieved from $\mathrm{C}$. alpina had a higher hatchability than those retrieved from $T$. totanus, possibly because their smaller gizzard caused less physical damage (Figuerola, Green \& Santamaria, 2002). However, in the field, both species can regurgitate some food items as pellets. Field data suggest that Artemia cysts from T. totanus pellets have a higher hatchability than cysts found in faeces (Green et al., 2005; Sanchez et al., 2007). We did not observe any pellets during or after our experiment, but it remains possible that some pellets were produced after the birds were released, and that therefore we underestimated both survival of cysts and retention time in T. totanus. Proctor (1968) found that some shorebirds regurgitate seeds more than a week after ingestion.

Although we did not record retention times of more than $12 \mathrm{~h}$, viable cysts of A. franciscana were retained for up to $24 \mathrm{~h}$ in the gut of Killdeer Charadrius vociferus Linnaeus (Proctor, Malone \& deVlaming, 1967). Similarly, intact Artemia cysts were retained in the greater flamingo Phoenicopterus ruber Linnaeus and shelduck Tadorna tadorna Linnaeus for up to $38 \mathrm{~h}$, and these two species are also likely to be major vectors of Artemia (MacDonald, 1980). The flamingo has recently become particularly abundant in Mediterranean sites frequented by Artemia (Rendó $\mathrm{n}$ et al., 2008). The mean and maximum retention times of invertebrate eggs we recorded were relatively low compared to experiments with dabbling ducks Anas spp., which are larger birds. Mean retention time of A. franciscana cysts was $4 \mathrm{~h}$ in mallards Anas platyrhynchos Linnaeus, and the maximum was $28 \mathrm{~h}$ (Charalambidou et al., 2005), although this duck species is not known to be a vector of brine shrimps. Maximum retention time was $44 \mathrm{~h}$ for C. mucedo statoblasts (Charalambidou et al., 2003b) and $22 \mathrm{~h}$ for B. longimanus eggs (Charalambidou et al., 2003a). 
Redshank and dunlin fly at $48-56 \mathrm{~km} \mathrm{~h}^{{ }^{1}}$, and therefore, our results indicate that most Artemia cysts could be dispersed less than $100 \mathrm{~km}$, even if a bird takes flight shortly after feeding. However, this is enough to allow the spread of A. franciscana around the Mediterranean on a step-by-step basis between neighbouring salt pan complexes (Amat et al., 2005). Furthermore, the maximum retention time we observed suggests that cysts are sometimes dispersed up to $600 \mathrm{~km}$. The most important barrier to the spread of the sexual A. franciscana is likely to be the Allee effect (Sarnelle \& Knapp, 2004), especially when introduced into enormous populations of native brine shrimps.

The ecology of different waterbird species has a fundamental influence on their role as dispersal vectors (Green, Figuerola \& Sanchez, 2002). Redshank and dunlin both have populations of hundreds of thousands of individuals moving through the Mediterranean region, but differ in their breeding range and migratory behaviour (Wetlands International, 2006) and are likely to have different roles in the dispersal of Artemia. Dunlin breed further north and only pass through the Mediterranean during migration, when they are best suited to disperse cysts between sites differing in latitude. Redshank are present in the region throughout the year, disperse cysts at various times of the year (Sanchez et al., 2007) and are well suited to moving shrimps between sites at differing longitude. However, ringing recoveries from the Odiel marshes show that many Redshank also move between this site and northern Europe (Sanchez, Green \& Castellanos, 2006b).

There is no reliable information on the number of exotic invertebrate taxa introduced into different continents, largely because many are small, cryptic and only studied in detail in a few places. The dispersal of many of these species has been linked to transport by humans (Havel \& Shurin, 2004; Holeck et al., 2004). In the case of invasive bivalves, such as the zebra mussel Dreissena polymorpha Pallass, experiments suggest they do not survive passage through the avian gut (Thompson \& Sparks, 1977; Johnson \& Carlton, 1996), although they could potentially be carried on the outside of birds (Green \& Figuerola, 2005). However, a broad range of aquatic invertebrates are known to disperse via waterbirds, including rotifers, copepods, branchiopods, ostracods, bryozoans, nematodes and dipterans (Green \& Sanchez, 2006; Frisch, Green \& Figuerola, 2007; Brochet et al., 2010b), although there remains little information at the species level. Hence, we suggest that birds have a role in the spread of numerous exotic species, and A. franciscana gives us an example of how readily waterbirds can act as vectors.

\section{Acknowledgments}

The first author was supported by a pre-doctoral grant from the Ministerio de Ciencia y Tecnologia, and the third by a Ramon y Cajal contract and a project financed by the Consejería de Medio Ambiente, Junta de Andalucía. Costs for the second author were supported by the Plan Andaluz de Investigación. Additional funding was provided by the European Science Foundation project 'BIOPOOL' and Spanish Ministerio de Educació n y Ciencia (projects CGL2005-02306/BOS, CGL2006-27125E/BOS, CGL2006-05085/BOS and CGL2010-16028/BOS, including FEDER funds). We are indebted to the zoological and botanical gardens at Jerez de la Frontera for facilities and support. Francesco Bufarini provided essential help in the laboratory.

\section{References}

Amat F., Hontoria F., Navarro J.C., Vieira N. \& Mura G. (2007) Biodiversity loss in the genus Artemia in the Western Mediterranean Region. Limnética, 26, 177-194.

Amat F., Hontoria F., Ruiz O., Green A.J., Sanchez M.I., Figuerola J. et al. (2005) The American brine shrimp as an exotic invasive species in the western Mediterranean. Biological Invasions, 7, 37-47.

Brochet A.L., Gauthier-Clerc M., Guillemain M., Fritz H., Waterkeyn A., Baltanas A. et al. (2010a) Field evidence of dispersal of branchiopods, ostracods and bryozoans by teal (Anas crecca) in the Camargue (southern France). Hydrobiologia, 637, 255-261.

Brochet A.L., Guillemain M., Fritz H., Gauthier-Clerc M. \& Green A.J. (2009) The role of migratory ducks in the longdistance dispersal of native plants and the spread of exotic plants in Europe. Ecography, 32, 919-928.

Brochet A.L., Guillemain M., Fritz H., Gauthier-Clerc M. \& Green A.J. (2010b) Plant dispersal by teal (Anas crecca) in the Camargue: duck guts are more important than their feet. Freshwater Biology, 55, 1262-1273.

Brochet A.L., Guillemain M., Gauthier-Clerc M., Fritz H. \& Green A.J. (2010c) Endozoochory of Mediterranean aquatic plant seeds by teal after a period of desiccation: determinants of seed survival and influence of retention time on germinability and viability. Aquatic Botany, 93, 99-106.

Charalambidou I., Ketelaars H.A.M. \& Santamaría L. (2003a) Endozoochory by ducks: influence of developmental stage of Bythotrephes diapause eggs on dispersal probability. Diversity and Distributions, 9, 367-374.

Charalambidou I., Santamaría L. \& Figuerola J. (2003b) How far can the freshwater bryozoan Cristatella mucedo disperse in duck guts? Archiv für Hydrobiologie, 157, 547-554.

Charalambidou I., Santamaria L., Jansen C. \& Nolet B.A. (2005) Digestive plasticity in Mallard ducks modulates 
dispersal probabilities of aquatic plants and crustaceans. Functional Ecology, 19, 513-519.

Espinar J.L., Garcia L.V., Figuerola J., Green A.J. \& Clemente L. (2004) Helophyte germination in a Mediterranean salt marsh: gut-passage by ducks changes seed response to salinity. Journal of Vegetation Science, 15, 315-322.

Figuerola J., Charalambidou I., Santamaria L. \& Green A.J. (2010) Internal dispersal of seeds by waterfowl: effect of seed size on gut passage time and germination patterns. Naturwissenschaften, 97, 555-565.

Figuerola J. \& Green A.J. (2002a) Dispersal of aquatic organisms by waterbirds: a review of past research and priorities for future studies. Freshwater Biology, 47, 483-494.

Figuerola J. \& Green A.J. (2002b) How frequent is external transport of seeds and invertebrate eggs by waterbirds? A study in Doñana, SW Spain Archiv für Hydrobiologie, 155, 557-565.

Figuerola J., Green A.J. \& Santamaria L. (2002) Comparative dispersal effectiveness of wigeongrass seeds by waterfowl wintering in south-west Spain: quantitative and qualitative aspects. Journal of Ecology, 90, 989-1001.

Frisch D., Green A.J. \& Figuerola J. (2007) High dispersal capacity of a broad spectrum of aquatic invertebrates via waterbirds. Aquatic Sciences, 69, 568-574.

Georgiev B.B., Sanchez M.I., Vasileva G.P., Nikolov P.N. \& Green A.J. (2007) Cestode parasitism in invasive and native brine shrimps (Artemia spp.) as a possible factor promoting the rapid invasion of $\mathrm{A}$. franciscana in the Mediterranean region. Parasitology Research, 101, 1647-1655.

Green A.J. \& Figuerola J. (2005) Recent advances in the study of long-distance dispersal of aquatic invertebrates via birds. Diversity and Distributions, 11, 149-156.

Green A.J., Figuerola J. \& Sanchez M.I. (2002) Implications of waterbird ecology for the dispersal of aquatic organisms. Acta Oecologica - International Journal of Ecology, 23, 177-189.

Green A.J., Jenkins K.M., Bell D., Morris P.J. \& Kingsford R.T. (2008) The potential role of waterbirds in dispersing invertebrates and plants in arid Australia. Freshwater Biology, 53, 380-392.

Green A.J. \& Sanchez M.I. (2006) Passive internal dispersal of insect larvae by migratory birds. Biology Letters, 2, 55-57.

Green A.J., Sanchez M.I., Amat F., Figuerola J., Hontoria F., Ruiz O. et al. (2005) Dispersal of invasive and native brine shrimps Artemia (Anostraca) via waterbirds. Limnology and Oceanography, 50, 737-742.

Hahn S., Bauer S. \& Klaassen M. (2008) Quantification of allochthonous nutrient input into freshwater bodies by herbivorous waterbirds. Freshwater Biology, 53, 181-193.

Havel J.E. \& Shurin J.B. (2004) Mechanisms, effects, and scales of dispersal in freshwater zooplankton. Limnology and Oceanography, 49, 1229-1238.

Holeck K.T., Mills E.L., MacIsaac H.J., Dochoda M.R., Colautti R.I. \& Ricciardi A. (2004) Bridging troubled waters: biological invasions, transoceanic shipping, and the Laurentian Great Lakes. BioScience, 54, 919-929.
Johnson L.E. \& Carlton J.T. (1996) Post-establishment spread in large scale invasions: dispersal mechanisms of the zebra mussel Dreissena polymorpha. Ecology, 77, 1686-1690.

Lavens P. \& Sorgeloos P. (1996) Manual on the Production and Use of Live Food for Aquaculture. FAO Fisheries Technical Paper 361. FAO, Rome.

MacDonald G.H. (1980) The use of Artemia cysts as food by the flamingo (Phoenicopterus ruber roseus) and the shelduck (Tadorna tadorna). In: The Brine Shrimp Artemia. Ecology, Culturing, Use in Aquaculture (Eds. G. Persoone, P. Sorgeloos, O. Roels \& E. Jaspers), pp. 97-104. Universa Press, Wetteren.

Malone C.R. (1965) Dispersal of aquatic gastropods via the intestinal tract of water birds. Nautilus, 78, 135-139.

Muñ oz J., Gomez A., Green A.J., Figuerola J., Amat F. \& Rico C. (2010) Evolutionary origin and phylogeography of the diploid obligate parthenogen Artemia parthenogenetica (Branchiopoda: Anostraca). PLoS ONE, 5, e11932.

Muñ oz J. \& Pacios F. (2010) Global biodiversity and geographical distribution of diapausing aquatic invertebrates: the case of the cosmopolitan Brine Shrimp, Artemia (Branchiopoda, Anostraca). Crustaceana, 83, 465-U117.

Proctor V.W. (1968) Long-distance dispersal of seeds by retention in digestive tract of birds. Science, 160, 321-322.

Proctor V.W., Malone C.R. \& deVlaming V.L. (1967) Dispersal of aquatic organisms: viability of disseminules recovered from the intestinal tract of captive Killdeer. Ecology, 48, 672-676.

Rendó n M.A., Green A.J., Aguilera E. \& Almaraz P. (2008) Status, distribution and long term changes in the waterbird community wintering in Doñana, south-west Spain. Biological Conservation, 141, 1371-1388.

Sanchez M.I., Green A.J., Amat F. \& Castellanos E.M. (2007) Transport of brine shrimps via the digestive system of migratory waders: dispersal probabilities depend on diet and season. Marine Biology, 151, 1407-1415.

Sanchez M.I., Green A.J. \& Castellanos E.M. (2005) Seasonal variation in the diet of Redshank Tringa totanus in the Odiel Marshes, southwest Spain: a comparison of faecal and pellet analysis. Bird Study, 52, 210-216.

Sanchez M.I., Green A.J. \& Castellanos E.M. (2006a) Temporal and spatial variation of an aquatic invertebrate community subjected to avian predation at the Odiel salt pans (SW Spain). Archiv für Hydrobiologie, 166, 199-223.

Sanchez M.I., Green A.J. \& Castellanos E.M. (2006b) Internal transport of seeds by migratory waders in the Odiel marshes, south-west Spain: consequences for long-distance dispersal. Journal of Avian Biology, 37, 201-206.

Sanchez M.I., Hortas F., Figuerola J. \& Green A.J. (2009) Sandpipers select red brine shrimps rich in both carotenoids and parasites. Ethology, 115, 196-200.

SAS Institute Inc. (2008) Glimmix Procedure, SAS 9.2. SAS Institute Inc., Cary. 
Sarnelle O. \& Knapp R.A. (2004) Zooplankton recovery after fish removal: limitations of the egg bank. Limnology and Oceanography, 49, 1382-1392.

Sekercioglu C.H. (2006) Increasing awareness of avian ecological function. Trends in Ecology \& Evolution, 21, 464-471. StatSoft Inc. (2001) Statistica, version 6. StatSoft Inc., Tulsa.

Strayer D.L. (2010) Alien species in fresh waters: ecological effects, interactions with other stressors, and prospects for the future. Freshwater Biology, 55, 152-174.

Thompson C.M. \& Sparks R.E. (1977) Improbability of dispersal of adult asiatic clams, Corbicula manilensis, via the intestinal tract of migratory waterfowl. American Midland Naturalist, 98, 219-223.

Van Stappen G., Yu H.Y., Wang X.M., Hoffman S., Cooreman K., Bossier P. et al. (2007) Occurrence of allochthonous Artemia species in the Bohai Bay area, PR China, as confirmed by RFLP analysis and laboratory culture tests. Fundamental and Applied Limnology, 170, 21-28.

Waterkeyn A., Vanschoenwinkel B., Elsen S., Anton-Pardo M., Grillas P. \& Brendonck L. (2010) Unintentional dispersal of aquatic invertebrates via footwear and motor vehicles in a Mediterranean wetland area. Aquatic Conservation: Marine and Freshwater Ecosystems, 20, 580-587.

Wetlands International (2006) Waterbird Population Estimates, 4th edn. Wetlands International, Wageningen, the Netherlands.

Whitney K.D. \& Gabler C.A. (2008) Rapid evolution in introduced species, 'invasive traits' and recipient communities: challenges for predicting invasive potential. Diversity and Distributions, 14, 569-580.

Williamson M.H. ed. (1996) Biological Invasions. Chapman \& Hall, UK.

Wolfe L.M. (2002) Why alien invaders succeed: support for the escape-from-enemy hypothesis. American Naturalist, $160,705-711$.

(Manuscript accepted 17 June 2012) 